\title{
Modified photoperiods and light intensities for grow-out production of nile tilapia (O. niloticus) under indoor tank culture system
}

\author{
Marvin Cinense ${ }^{1,}{ }^{*}$, Ireneo Agulto ${ }^{1}$, Armando Espino Jr. ${ }^{1}$, Romeo Gavino ${ }^{1}$, Emmanuel Sicat ${ }^{1}$ and Victorino Taylan ${ }^{1}$ \\ ${ }^{1}$ Department of Agricultural and Biosystems Engineering Department, College of Engineering, Central Luzon State University, Science \\ City of Munoz, Nueva Ecija, Philippines 3120
}

\begin{abstract}
The study aimed to evaluate the effect of modified photoperiods and light intensities on grow-out production of tilapia under indoor tank culture system; specifically on water quality and on growth performance of tilapia. The study was conducted inside the greenhouse and considered two factors: photoperiod (24L:0D, 20L:4D and 16L:8D); and light intensity (40 watts $\mathrm{m}^{-2}, 60$ watts $\mathrm{m}^{-2}$ and 80 watts $\mathrm{m}^{-2}$ ); also, a control treatment was set-up outside the greenhouse to receive the normal environmental condition. Light manipulations inside the greenhouse were able to sustain the water quality within the desirable level for tilapia cultured in tank; while control tanks shows high water quality variation. Growth performance of tilapia cultured in tank responds positively in prolonged photoperiod at different light intensities. However, light manipulation gave insignificant difference on feed conversion ratio and survival rate compared to normal condition. Results indicated that 20-hours photoperiod and 40 watts $\mathrm{m}^{-2}$ light intensity is just enough to sustain the recommended water quality and better growth performance of the cultured tilapia in indoor tank system. It can be concluded that longer photoperiod and restrained light intensity can improved the growth performance of tilapia under indoor tank culture.
\end{abstract}

\section{Introduction}

Aquaculture is affected by the impact of climate change such as increasing temperature and sudden changes in local weather condition that can cause low production or leading to fish kill. Also, increasing competition for freshwater may lead to the reduction of suitable areas for aquaculture. Indoor aquaculture has the potential and is a good alternative for outdoor production. However, it is necessary to determine its optimum environmental condition to maximize productivity. One of the major concerns in indoor production is the absence of sunlight; and currently, some information is available concerning the effects of artificial photoperiod and light intensity on the growth performance of tilapia for indoor tank culture.

This study generally aimed to devise modified photoperiods and light intensities for grow-out production of Nile tilapia (Oreochromis niloticus) under indoor tank culture system. Specifically, it aimed to: evaluate the effect of light manipulation on water quality and to analyze the effect of photoperiods and light intensities on the growth performance of tilapia under indoor tank culture system.

\section{Materials and methods}

The study considered two light manipulation factors arranged in split-plot: the photoperiod as main plot; $\mathrm{P}_{1}$ (24L:0D), $\mathrm{P}_{2}$ (20L:4D) and $\mathrm{P}_{3}$ (16L:8D); and, light intensity as sub-plot; $\mathrm{L}_{1}\left(40\right.$ watts $\left.\mathrm{m}^{-2}\right), \mathrm{L}_{2}\left(60\right.$ watts $\left.\mathrm{m}^{-2}\right)$ and $\mathrm{L}_{3}\left(80\right.$ watts $\left.\mathrm{m}^{-2}\right)$; also, a control treatment tanks were constructed outside to receive the normal outside condition. A total of 30 plastic tanks were used each having a 1000-liter or 1 cubic meter capacity to represent each treatment and was replicated three times.

The experiment was conducted inside the greenhouse structure. A net covering ( $80 \%$ shading) was used to minimize the effect of sunlight to light manipulation treatments. Light intensity in each photoperiod tank was provided by compact fluorescent lamps installed about $100 \mathrm{~cm}$ above the water surface. For light intensity treatment $\mathrm{L}_{1}$, two 20 -watts compact fluorescent bulbs were installed; for $\mathrm{L}_{2}$, three 20 -watts were installed; and for $\mathrm{L}_{3}$, four 20-watts were installed. Each fish tank (except control) was covered with black cloth to minimize the effect of natural sunlight at the same time isolating them from the other treatments (Fig. 1).

All fish samples were acclimatized for three weeks under 12L:12D photoperiod [1]; to make sure that the effect of fish kill is due to the experimental treatments and not on fish stress or other outside factor. During this period, dead fish were removed. Prior to the start of the 
experiment, the fish were starved for 24 hours, and their body weights measured. The tilapia stocked has an initial average weight of $25.0 \pm 0.5$ grams. Feeding was done manually three times a day with the feeding rate of $4 \%$ biomass.

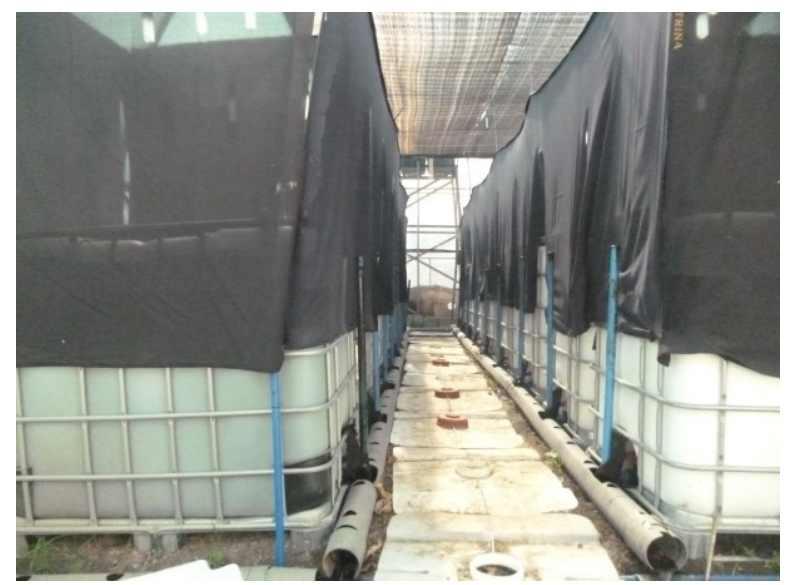

Fig. 1. The experimental set-up inside the greenhouse.

Ten fish samples per tank were used to determine the growth performance of tilapia in terms of weight gain (BWG), specific growth rate (SGR) and feed conversion ratio (FCR) every three weeks. Survival rate (SR) per tank were monitored daily. Also, uneaten feeds were measured and were deducted to the total feeds supplied [2]. These parameters were computed based on the following equations:

$$
\begin{gathered}
B W G=W_{f}-W_{i} \\
S G R=\left(\operatorname{Ln} W_{f}-\operatorname{Ln} W_{i}\right) * 100 / t \\
F C R=D_{f} /\left(W_{f}-W_{i}\right) \\
S R=N_{f} * 100 / N_{i}
\end{gathered}
$$

where:

$$
\begin{aligned}
& W_{i}=\text { initial wet weight (grams) } \\
& W_{f}=\text { final wet weight (grams) } \\
& t=\text { time interval (days) } \\
& N_{i}=\text { initial number of fishes stocked } \\
& N_{f}=\text { final number of fishes stocked } \\
& D_{f}=\text { dry feed intake }
\end{aligned}
$$

Water quality such as water temperature, dissolved oxygen (DO), $\mathrm{pH}$ and total ammonia were monitored daily using a multi-parameter water quality meter. Data on un-ionized ammonia were tabulated based on total ammonia readings using the temperature-pH table [3]. Water exchange and air blower were used to sustain the desirable water quality level for tilapia culture.

\section{Results and discussion}

\subsection{Water quality}

Good water quality is essential for growth and survival of the cultured species, and it must be monitored regularly to serve as guide for managing the aquaculture project. In tilapia production, water quality such as temperature, $\mathrm{pH}$, ammonia and dissolved oxygen are some of the parameters to be considered to attain better growth performance and higher yield.

Water temperature in light manipulation (photoperiod and light intensity) treatment tanks ranged from $25-28{ }^{\circ} \mathrm{C}$ in the morning and $27-29{ }^{\circ} \mathrm{C}$ in the afternoon. It shows that even by exposing the treatment tanks into longer photoperiod from 16 hours up to 24 hours or by increasing the light intensity from 40 to 80 watts $\mathrm{m}^{-2}$, it cannot significantly increase the water temperature in tanks. While, control tanks' temperature ranged from $24-28{ }^{\circ} \mathrm{C}$ in the morning and $28-31{ }^{\circ} \mathrm{C}$ in the afternoon. Record shows that water temperature in control tank is higher in the afternoon than the water temperature inside the greenhouse as it was influenced by the ambient air temperature (Fig. 2 and Fig. 3).

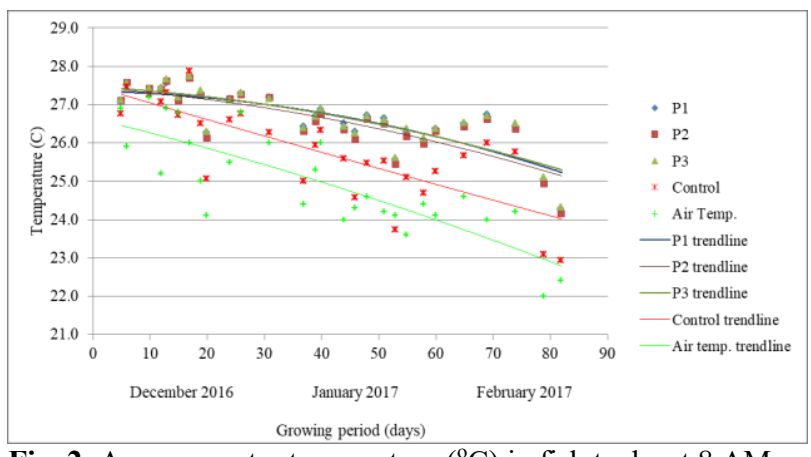

Fig. 2. Average water temperature $\left({ }^{\circ} \mathrm{C}\right)$ in fish tanks at $8 \mathrm{AM}$ for the different photoperiod treatments.

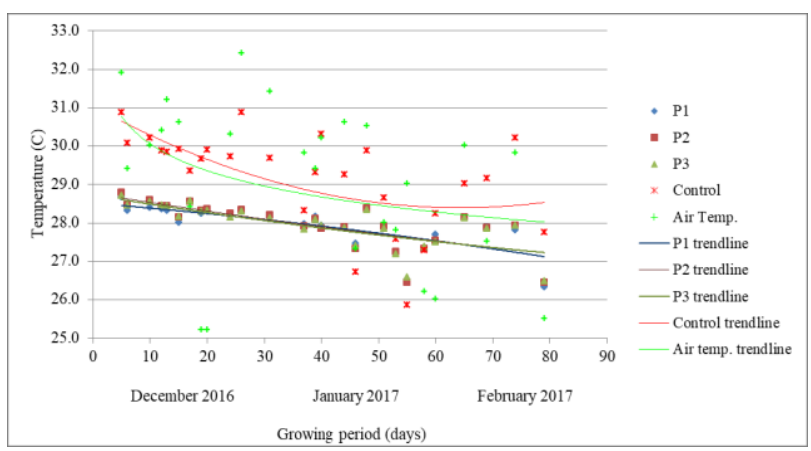

Fig. 3. Average water temperature $\left({ }^{\circ} \mathrm{C}\right)$ in fish tanks at $2 \mathrm{PM}$ for the different photoperiod treatments.

Water $\mathrm{pH}$ in light manipulation treatment tanks ranged from 7.2 to 7.6 in the morning and 7.1 to 7.5 in the afternoon. It shows that water $\mathrm{pH}$ is not directly influence by the increase or decrease of photoperiod and light intensity imposed in the study. While control tanks recorded 7.2 to $8.0 \mathrm{pH}$ in the morning and 7.3 to 9.0 in the afternoon. Higher $\mathrm{pH}$ reading on control tanks in the afternoon can be attributed to the presence of plankton (Fig. 4 and Fig. 5).

Ammonia toxicity is dependent on both $\mathrm{pH}$ and temperature, wherein higher $\mathrm{pH}$ and water temperature make ammonia more toxic. Results showed that the average un-ionized ammonia during the initial stage of the growing period were above the desirable level in all light manipulation and control treatment tanks, but for the succeeding growing periods, it was within the 
acceptable level [4]. However, control tanks recorded high levels of un-ionized ammonia in the afternoon until the $43^{\text {rd }}$ day of growing period, and during this period higher temperature and $\mathrm{pH}$ levels were also recorded which resulted to high mortality in these tanks (Fig. 6 and Fig. 7).

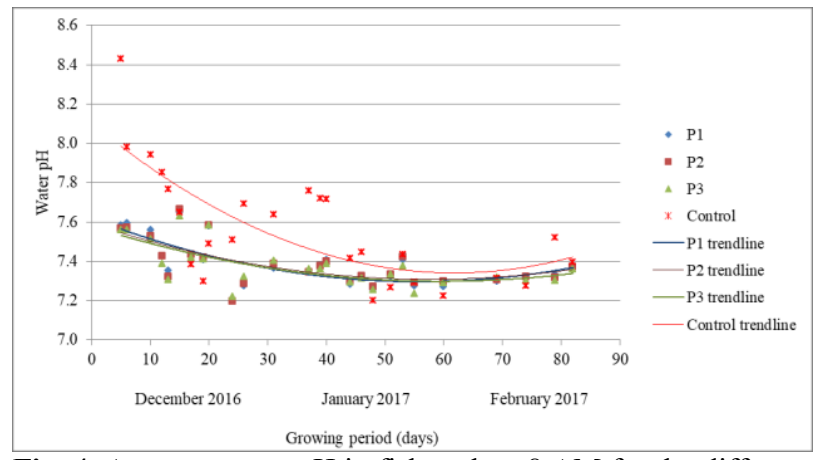

Fig. 4. Average water $\mathrm{pH}$ in fish tank at $8 \mathrm{AM}$ for the different photoperiod treatments.

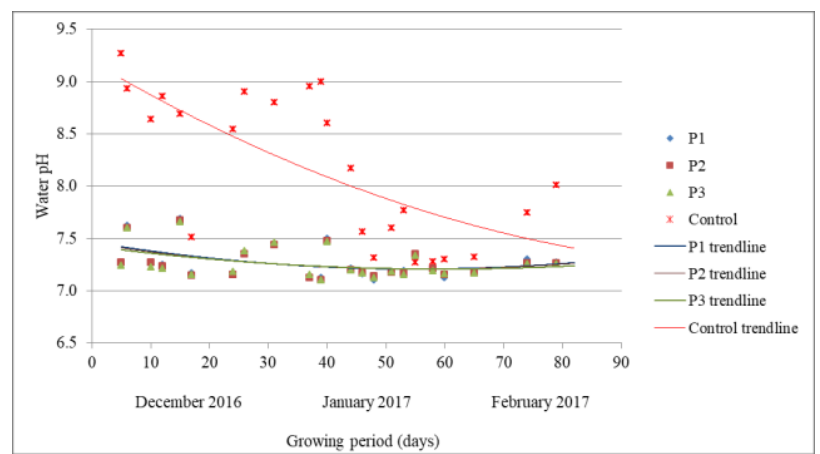

Fig. 5. Average water $\mathrm{pH}$ in fish tank at $2 \mathrm{PM}$ for the different photoperiod treatments.

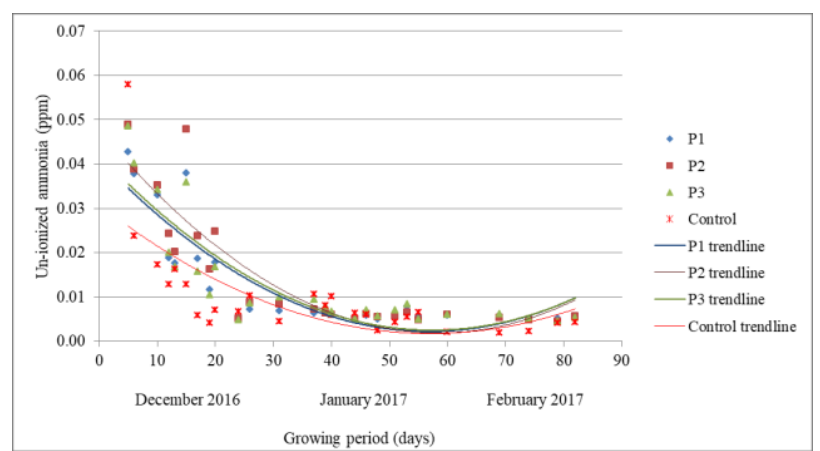

Fig. 6. Average un-ionized ammonia (ppm) in fish tank at 8 $\mathrm{AM}$ for the different photoperiod treatments.

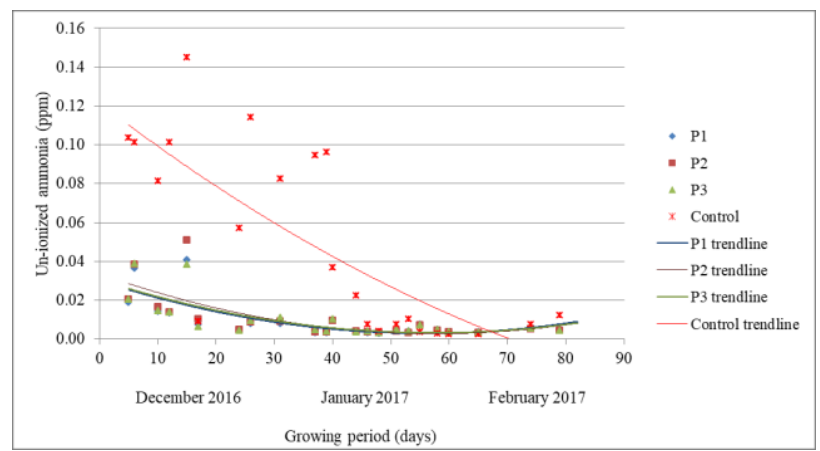

Fig. 7. Average un-ionized ammonia (ppm) in fish tank at 2 PM for the different photoperiod treatments.
Low DO was recorded for the different light manipulation treatment tanks throughout the growing period which ranged from 1.0 to $3.0 \mathrm{ppm}$. Similarly, the DO level recorded during the morning observations in the control tanks were even lower $(<2.0 \mathrm{ppm})$. However, it goes from normal to high levels in the afternoon which ranged from 4.0 to 14.0 ppm (Fig. 8 and Fig. 9).

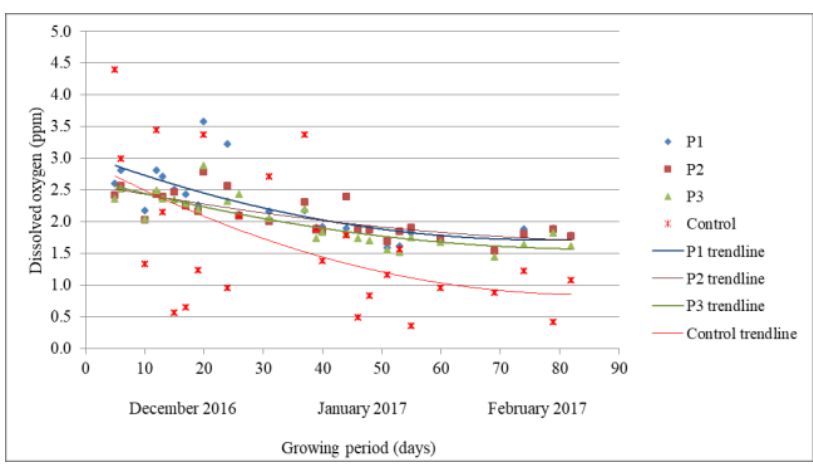

Fig. 8. Average dissolved oxygen (ppm) in fish tank at 8 AM for the different photoperiod treatments.

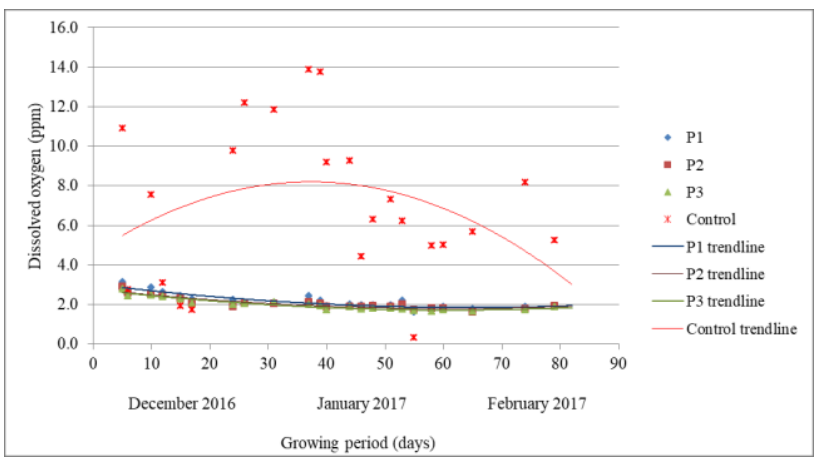

Fig. 9. Average dissolved oxygen (ppm) in fish tank at 2 PM for the different photoperiod treatments.

\subsection{Growth performance}

Tilapia stocked has an initial average weight of $25.0 \pm$ 0.5 grams prior to the start of the experiment. Analysis on total body weight gain (BWG), specific growth rate (SGR), feed conversion ratio (FCR) and survival rate (SR) showed no significant differences among the means at different photoperiod and light intensity treatments and their interactions (Tables 1 to 4). However, comparing photoperiod treatments to control shows that the total body weight gain of tilapia under 20L:4D treatment was significantly higher by $52 \%$ than those under the control treatment (C); while means under 24L:0D and 16L:8D were not, with only $35 \%$ and $24 \%$ increase respectively (Table 5).

Table 1. Total body weight gain (grams) of fish subjected to different photoperiods and light intensities.

\begin{tabular}{|c|c|c|c|c|}
\hline Treatment & $\mathrm{L}_{1}$ & $\mathrm{~L}_{2}$ & $\mathrm{~L}_{3}$ & Mean \\
\hline $\mathrm{P}_{1}$ & 55.60 & 49.43 & 49.83 & 51.62 \\
\hline $\mathrm{P}_{2}$ & 56.17 & 56.83 & 60.70 & 57.90 \\
\hline $\mathrm{P}_{3}$ & 40.52 & 53.13 & 48.03 & 47.23 \\
\hline Mean & 50.76 & 53.13 & 52.86 & \\
\hline
\end{tabular}

Means with the same subscript letter or without subscripts are not significantly different at 0.05 level of significance. 
Table 2. Specific growth rate (\%/day) of fish subjected to different photoperiods and light intensities.

\begin{tabular}{|c|c|c|c|c|}
\hline Treatment & $\mathrm{L}_{1}$ & $\mathrm{~L}_{2}$ & $\mathrm{~L}_{3}$ & Mean \\
\hline $\mathrm{P}_{1}$ & 1.26 & 1.16 & 1.21 & 1.21 \\
\hline $\mathrm{P}_{2}$ & 1.28 & 1.28 & 1.30 & 1.29 \\
\hline $\mathrm{P}_{3}$ & 0.94 & 1.16 & 1.15 & 1.09 \\
\hline Mean & 1.16 & 1.20 & 1.22 & \\
\hline
\end{tabular}

Means with the same subscript letter or without subscripts are not significantly different at 0.05 level of significance.

Table 3. Feed conversion ratio of fish subjected to different photoperiods and light intensities.

\begin{tabular}{|c|c|c|c|c|}
\hline Treatment & $\mathrm{L}_{1}$ & $\mathrm{~L}_{2}$ & $\mathrm{~L}_{3}$ & Mean \\
\hline $\mathrm{P}_{1}$ & 2.64 & 3.08 & 2.93 & 2.88 \\
\hline $\mathrm{P}_{2}$ & 2.70 & 2.72 & 2.50 & 2.64 \\
\hline $\mathrm{P}_{3}$ & 3.34 & 2.99 & 3.27 & 3.20 \\
\hline Mean & 2.89 & 2.93 & 2.90 & \\
\hline
\end{tabular}

Means with the same subscript letter or without subscripts are not significantly different at 0.05 level of significance.

Table 4. Total body weight gain (grams) of fish subjected to different photoperiods and light intensities.

\begin{tabular}{|c|c|c|c|c|}
\hline Treatment & $\mathrm{L}_{1}$ & $\mathrm{~L}_{2}$ & $\mathrm{~L}_{3}$ & Mean \\
\hline $\mathrm{P}_{1}$ & 71.11 & 75.56 & 66.67 & 71.11 \\
\hline $\mathrm{P}_{2}$ & 91.11 & 93.33 & 84.44 & 89.63 \\
\hline $\mathrm{P}_{3}$ & 75.56 & 60.00 & 84.44 & 73.33 \\
\hline Mean & 79.26 & 76.30 & 78.52 & \\
\hline
\end{tabular}

Means with the same subscript letter or without subscripts are not significantly different at 0.05 level of significance.

Table 5. Performance of fish subjected to different photoperiods and light intensities.

\begin{tabular}{|c|c|c|c|c|c|c|c|}
\hline Para & $\begin{array}{c}24 \mathrm{~L}: \\
0 \mathrm{D}\end{array}$ & $\begin{array}{c}20 \mathrm{~L}: \\
4 \mathrm{D}\end{array}$ & $\begin{array}{c}16 \mathrm{~L}: \\
8 \mathrm{D}\end{array}$ & $\begin{array}{c}40 \\
\mathrm{w} \\
\mathrm{m}^{-2}\end{array}$ & $\begin{array}{c}60 \\
\mathrm{w} \\
\mathrm{m}^{-2}\end{array}$ & $\begin{array}{c}80 \\
\mathrm{w} \\
\mathrm{m}^{-2}\end{array}$ & $\mathrm{C}$ \\
\hline $\begin{array}{c}\text { BWG } \\
(\mathrm{g})\end{array}$ & $51_{\mathrm{ns}}$ & $57^{*}$ & $47_{\mathrm{ns}}$ & $50_{\mathrm{ns}}$ & $53^{*}$ & $52^{*}$ & 38 \\
\hline $\begin{array}{c}\text { SGR } \\
(\% / d a y)\end{array}$ & $1.2^{*}$ & $1.3^{*}$ & $1.1_{\mathrm{ns}}$ & $1.2^{*}$ & $1.2^{*}$ & $1.2^{*}$ & 0.9 \\
\hline FCR & $2.8_{\mathrm{ns}}$ & $2.6_{\mathrm{ns}}$ & $3.2_{\mathrm{ns}}$ & $2.9_{\mathrm{ns}}$ & $2.9_{\mathrm{ns}}$ & $2.9_{\mathrm{ns}}$ & 3.8 \\
\hline SR (\%) & $71_{\mathrm{ns}}$ & $89_{\mathrm{ns}}$ & $73_{\mathrm{ns}}$ & $79_{\mathrm{ns}}$ & $76_{\mathrm{ns}}$ & $78_{\mathrm{ns}}$ & 57 \\
\hline
\end{tabular}

Means in row with $n s$ is not significant or $*$ is significantly different compared to Control.

The BWG under light intensity $60 \mathrm{w} \mathrm{m}^{-2}$ and $80 \mathrm{w}$ $\mathrm{m}^{-2}$ were significantly differ when compared to those under the control treatment, with an average increase of $39.0 \%$ and $38.5 \%$ respectively; however, $40 \mathrm{w} \mathrm{m}^{-2}$ was not, with only $33.0 \%$ increase. Similarly, SGR under light manipulation treatments shows significant effect as compared to control, except treatment 16L:8D. Data explained fish in the extended photoperiod group had faster growth rate [5]; and this can be attributed to a rise in appetite and feed intake, better feed efficiency and/or elevated digestibility [6].

Results showed that outside condition is not good enough for growing tilapia under tank culture system. Likewise, having a 24-hour photoperiod for tilapia did not give any significant increase in the growth performance of tilapia. It shows that a 20-hour photoperiod is good enough for the growth of tilapia inside the modified environment.

\section{Conclusions}

Based on the result of the study, it can be concluded that (a) light manipulation treatment in indoor tank culture were able to sustain the water quality within the desirable level; (b) extended photoperiod can improved the growth performance of tilapia cultured in tank regardless of extent and intensity of light. However, subjecting the tilapia to 20 -hours photoperiod at 40 watts $\mathrm{m}^{-2}$ is good enough to improve the growth performance of tilapia in indoor tank culture compared to outside condition; (c) Feed conversion ratios of tilapia cultured in tank and treated with longer photoperiod at different light intensities showed better feed efficiency than those grown under normal daylight condition. However, exposing tilapia in tank for 20 -hours photoperiod at 40 watts $\mathrm{m}^{-2}$ is worthy enough for better feed consumption as compared to normal daylight condition; and, (d) lower mortality rate were recorded on tanks treated with longer photoperiod at different light intensities. Indoor tank culture of tilapia treated with 20-hours photoperiod at 40 watts $\mathrm{m}^{-2}$ can increased the survival rate of tilapia cultured in tank up to $90 \%$ as compared to outside environment with only $58 \%$ survival rate.

Special thanks to Engineering Research for Development and Technology - Department of Science and Technology (ERDTDOST).

\section{References}

1. A.K. Biswas, , M. Seoka, Y. Inoue, K. Takii, and H. Kumai. Aquaculture, 250: 666- 673 (2005)

2. M.A.M. Ali and A.M.I. El-Feky. Egyptian J. Anim. Prod. 50(3):186 -192 (2013)

3. K. Emerson, R.E. Lund, R.V. Thurston and R.C. Russo. J. Fish. Res. Board Can. 32: 2379-2383 (1975)

4. V. Suresh and R.C. Bhujel. Wiley-Blackwell Publishing Company, U K, pp 338-364 (2012)

5. C. Fuentes-Silva, G.M. Soto-Zarazua, I. TorresPacheco, R.G. Guevarra-Gonzalez, J.F. GarciaTrejo, A. Flores-Rangel, J. Caballero-Perez and A. Cruz-Hernandez. Int. J. of Agric. and Biol. ISSN Print: 1560-8530; ISSN Online: 1814-9596, 14524/2015/17-4-785-790, DOI:10.17957/IJAB/ 14.0016 (2015).

6. E.M. Vera Cruz and C.L. Brown. J. Fish Biol., 75: 130-141 (2009) 